\title{
Utilization of wood cell wall components
}

\author{
Yasumitsu Uraki $^{1} \cdot$ Keiichi Koda $^{1}$
}

Received: 28 April 2015/Accepted: 29 May 2015/Published online: 3 July 2015

(C) The Japan Wood Research Society 2015

\begin{abstract}
This article summarizes current utilizations of wood cell wall components in relation to biorefinery of woody biomass as a separation method of its constituents. Especially, utilization of isolated lignins, involving transformation and molding, are demonstrated with respect to productions of carbon fibers and their further functionalization, such as developments of activated carbon fibers and electrodes for second battery and electric double-layer capacitor.
\end{abstract}

Keywords Biorefinery $\cdot$ Lignin $\cdot$ Fusibility $\cdot$ Moldability

\section{Significance of utilization of wood cell wall components}

Wood cell wall consists of about $45 \%$ of cellulose and $20-30 \%$ of hemicelluloses and lignin. The ratio of hemicelluloses to lignin varies depending on the wood species, softwood or hardwood. In 1975, I. S. Goldstein demonstrated "potential for converting wood into plastics" in Science [1], where $95 \%$ of plastics or synthetic fibers in the USA at that time could be produced from wood components, lignin and cellulose. Especially, lignin was a

This review article is published to coincide with the 60th anniversary of the Japan Wood Research Society.

Yasumitsu Uraki

uraki@for.agr.hokudai.ac.jp

1 Research Faculty of Agriculture, Hokkaido University, N-9, W-9, Kita-ku, Sapporo 060-8589, Japan promising feedstock for thermosetting resins and aromatic polymers. Thereby, he claimed that woody biomass and its components were alternative feedstock to petroleum for polymer production. As a social background of the paper, the price of petroleum was increased due to its expanded consumption and shortage. In this century, the fear of shortage of fossil resources was slightly relieved because of the development of shale gas and oil. However, environmental impacts of consumption of fossil resources, such as exhausting greenhouse gases and reducing them from the Earth, are still of great concern. Therefore, utilization of woody biomass as a renewable alternative resource to fossil resources provides one of the solutions to such an environmental problem.

Fossil resources have two aspects: one, as a source of energy for fuel and electricity; and the other, as a source of raw material for organic chemicals and plastics. Electricity may be produced from some renewable resources, such as solar, wind and geothermal powers, but liquid fuel, such as bioethanol and biodiesel, and organic chemicals cannot be produced from such renewable resources. These organic materials can be prepared from another renewable resource such as wood and its constituents, instead. From this viewpoint, woody biomass and its components, the most abundant biomass on Earth, can be an alternative organic feedstock to fossil resources.

In this article, we introduce the recent progress in research for utilization of woody biomass components, in particular lignin. Now, lignin is merely used as an energy source for the pulp and paper industry. However, lignin is rarely used as a material source, except for utilization of lignosulfonate as a cement dispersant (including concrete) [2] and as an electrode of the second battery [3]. In the woody biomass utilization, lignin utilization is a key subject, as pointed out by Goldstein [1]. 


\section{Cellulose utilization}

$\beta-(1 \rightarrow 4)$ glucan, cellulose, has been used widely as a raw material for fabrics and paper since the dawn of time, and also as a first feedstock for man-made plastics (cellulose nitrate) and man-made fiber (rayon). Even now, it is a very important feedstock in the paper-making industry and in the production of cellulose derivatives, such as cellulose esters and ethers. Recently, cellulose derived from lowquality wood and annual herbaceous biomass has also been focused on as a feedstock of glucose for the production of bioethanol and other fermentation compounds. However, since there are piles of published articles on these applications of cellulose, very recent topics are briefly introduced in this section.

In the twenty-first century, nanotechnology has been focused on as an innovative technology. In the cellulose chemistry, cellulose nanofiber (CNF) also draws much attention worldwide as a novel type of reinforced fiber for plastics. As CNF consists of single or several microfibrils, its aspect ratio (length to diameter) is very large and its diameter ranges from 3 to $20 \mathrm{~nm}$. Therefore, CNFs, when dispersed in resin matrix, are invisible because of little scattering of visible light $[4,5]$, resulting in transparent resin or film. In addition, CNF-reinforced resin has very high mechanical strength due to the high elasticity of cellulose. Therefore, CNFs are considered to be a very unique reinforcing material as compared to conventional glass fibers in glass fiber-reinforced plastics.

Preparation of CNFs is classified mainly on two methods: one is the mechanical refining of delignified wood and pulp [5, 6], and the other is TEMPO-oxidation followed by gentle refining [7, 8]. The former method seems to be simpler and easier than the latter, but the diameter of the obtained fibers by mechanical refining is relatively large $(15-20 \mathrm{~nm})$. By contrast, TEMPO-oxidation gives thin fibers with a similar diameter to microfibrils (ca. $3 \times 3 \mathrm{~nm}$ ) of native cellulose. This phenomenon can be explained by the change in osmotic pressure and/or the occurrence of electrostatic repulsion between microfibrils, caused by the introduced carboxylate on the surface of microfibril by TEMPO-oxidation, which renders the following refinery and separation of fibers much easier. Development of CNF preparation method expands its application study in relation to production of composite materials. However, there is an obstacle: CNFs show low compatibility with hydrophobic compounds, synthetic polymers and their monomers. If we are to overcome the problem, it seems necessary that CNF-reinforced plastics should be developed like a conventional composite material, such as carbon fiber-reinforced plastics.

\section{Hemicellulose utilization}

Utilization of hemicelluloses, non-cellulosic heteropolysaccharides, as a feedstock for value-added material is another issue to achieve for the full utilization of woody biomass for chemicals. At present, however, most of the hemicelluloses, together with lignin, are removed during the pulping process, only to be burned to recover energy. The use of the current material, xylan, for conversion into furfural or xylitol is an exception [9].

There has recently been a lot of research work on functionalization of hemicelluloses that has been summarized in some excellent review articles [10, 11]. Extensive studies on carboxylic esters of hemicelluloses, for example, from wheat straw [12, 13] and sugarcane bagasse [14, 15], have been published. Development of films of arabinoxylan esters and their blends was also reported [16].

Of hemicelluloses, modification of xylan draws most attention, due to its abundance compared to the other hemicellulose components. Iwata and his research group have made efforts to develop xylan-based synthetic polymers. Xylan extracted from hardwood kraft pulp was acylated and characterized to observe the effect of their carbon chain length of the introduced acyl groups on the properties of the esters, and they successfully fabricated transparent film from those xylan esters [17, 18]. Based on their findings, Iwata and his coworkers developed polylactic acid blends with xylan esters [19, 20]. They further tried to develop xylan-based graft copolymers [21], and xylan butyrate-based triblock polymers [22]. They have also made attempts to fabricate glucomannan-based esters $[23,24]$.

Song and his coworkers have done extensive research on modified hemicellulose-related compounds. Corncob holocellulose was oxidized with hydrogen peroxide to develop dry-strength additive for paper making [25]. Carboxymethylated glucomannan was also modified to a paper-strengthening agent [26]. A prebiotic food additive was developed by producing xylooligosaccharides from xylan of triploid Populus tomentosa by xylanase treatment [27]. Application of a cereal-derived hemicellulose-rich by-product, namely $\beta$-D-glucan (a glucan fraction composed of $\beta-1,4-\mathrm{D}-$ and $\beta-1,3$-D-linkages) from oat processing, was also exploited. For example, $\beta$-D-glucan can be utilized as a paper-strengthening agent after being derivatized by TEMPO-mediated oxidation [28] and by carboxymethylation [29].

Galactglucomannan is another target to develop hemicellulose-based hydrogels [30], film laminates for oxygen barriers [31], cationized material [32], and multifunctional macroinitiator for single-electron transfer-mediated living radical polymerization [33]. 


\section{Lignin utilization}

The chemical and physical properties of lignin isolated from woods significantly vary depending on wood species, hardwood or softwood, and separation methods of wood cell wall components. Thereby, utilization of isolated lignins should be considered in relation to the separation processes. Chemical pulpings, such as kraft pulping and sulfite pulping, are considered to be representative separation processes of wood components. Sulfite lignin, or lignosulfonate, comprises a hydrophobic lignin backbone (phenylpropane unit) and anionic sulfonate groups. Accordingly, it has amphipathic nature in addition to water solubility [34, 35]. Based on such unique nature, lignosulfonate is widely utilized as a cement (and concrete) dispersant and electrode admixture for lead secondary battery as mentioned above. On the other hand, kraft lignin is insoluble in water, but soluble in aqueous alkaline solution. Accordingly, kraft lignin cannot be utilized in the application fields of lignosulfonate. Thus, even though both lignins are isolated from aqueous phase, the characteristics of the isolated lignins are quite different. In this section, current studies on lignin utilizations are introduced in relation to the chemical nature of various types of isolated lignins.

\section{Fusibility of organosolv lignins}

Organosolv pulping, using organic solvents as a cooking solvent, is often called solvolysis pulping. In organosolv pulping, the solvent used reacts with pulping feedstock, resulting in the introduction of the solvent molecule to pulp and lignin. Consequently, such an introduced moiety adds very unique characteristics to the resultant lignin, such as thermal fusibility and high reactivity. In synthetic polymers, they can be molded into various shapes on the basis of the fusible characteristics. Thereby, fusible property is very important in terms of moldability.

Atmospheric acetic acid pulping was carried out with 90-95\% aqueous acetic acid containing 0.1-0.32\% mineral acid, such as $\mathrm{HCl}$ and $\mathrm{H}_{2} \mathrm{SO}_{4}$. Since the pulping condition was similar to an acetylation condition, the separated components, pulp and lignin, was partially acetylated. As a result, the resultant lignin derived from its hardwood pulping (hardwood acetic acid lignin; HAL) showed fusibility [36], although susceptibility of the resultant pulp toward cellulolytic enzyme, cellulase, was very low. The fusibility of HAL was found to be attributed to the existence of the acetyl group and the polydispersity of its molecular mass. The acetylation of the hydroxyl group in lignin inhibited the formation of the hydrogen bond, giving rise to thermal mobility so that the acetyl group can act as an internal plasticizer. Low-molecular-mass fraction of HAL had higher thermal mobility than its high-molecular-mass fraction and, therefore, acted as an external plasticizer. This synergy effect contributed to the fusibility of HAL. Afterward, thermal fusibility was found in most organosolv lignins, such as alcell lignin [37] and cresol lignin [38]. To these organosolv lignins, solvent molecules were also introduced; the molecules were found to bind at the $\mathrm{C} \alpha$ and $\mathrm{C} \gamma$ positions under acidic conditions in organosolv pulpings. Hydroxy groups $\mathrm{C} \alpha$ and $\mathrm{C} \gamma$ positions were first protonated and then subjected to nucleophilic substitution reaction accompanied by elimination of water, as shown in Fig. 1 .

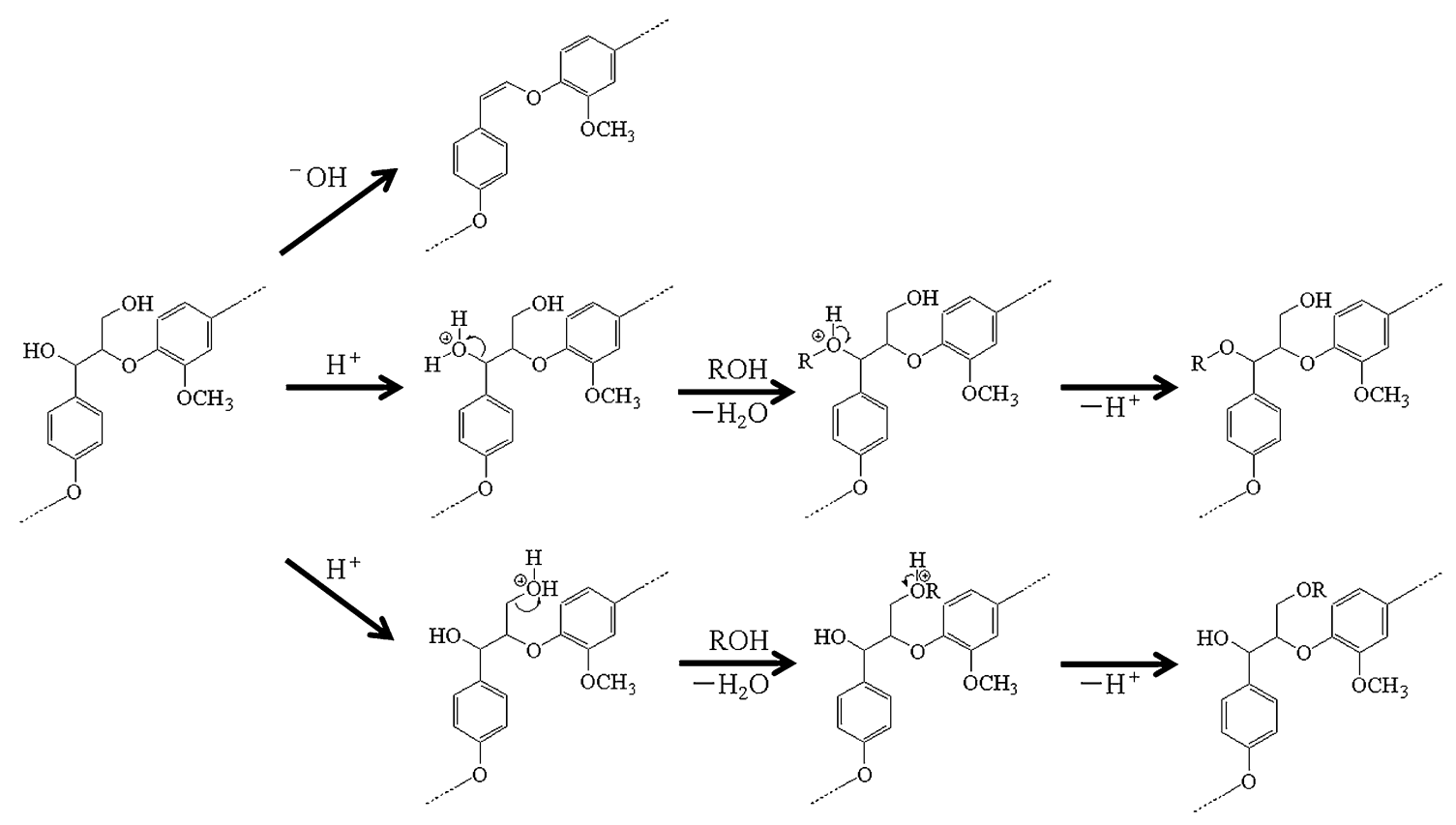

Fig. 1 The proposed chemical reactions of lignin during isolation processes, organosolv pulping and alkaline pulping from wood 
Fig. 2 Production scheme of carbon fibers and activated carbon fibers from isolated lignins

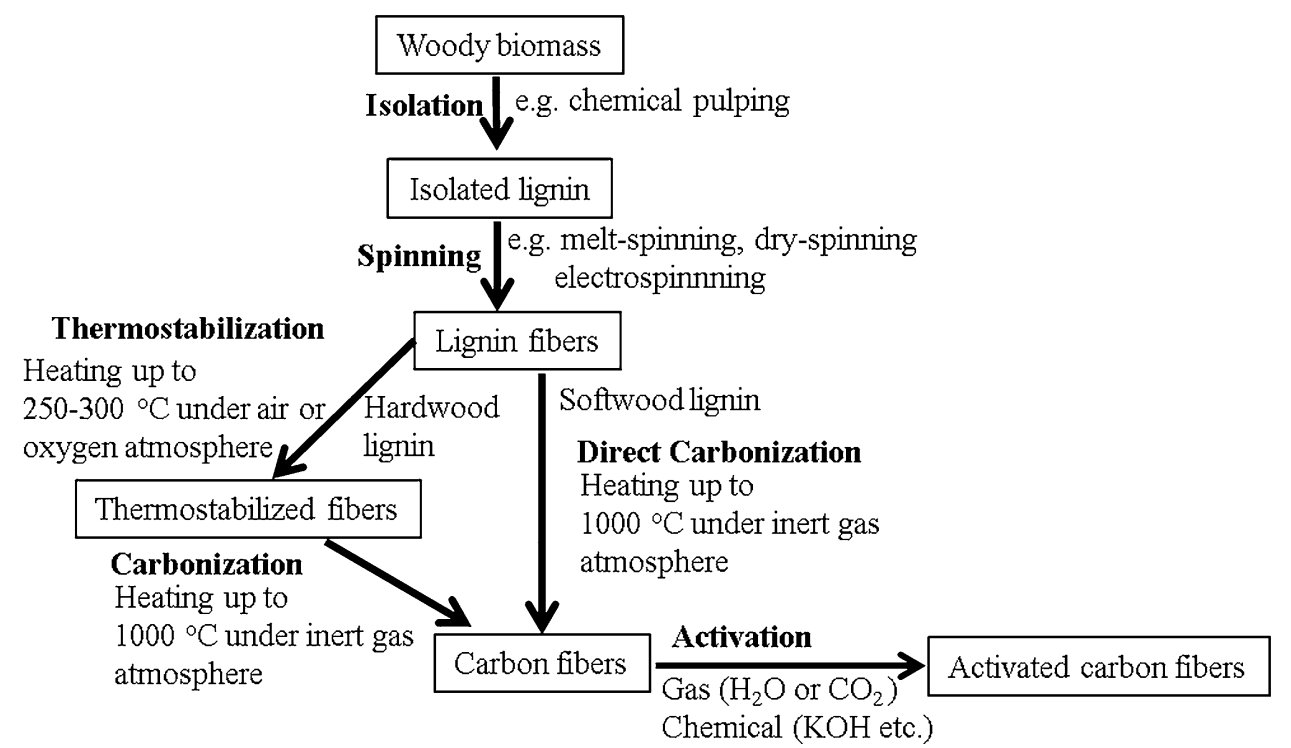

The bound solvent moieties acted as the internal plasticizer [39]. In addition, such fusible lignins were isolated from hardwood.

Softwood acetic acid lignin (SAL), however, did not show fusibility. The reason was attributed to the structure of the lignin, which was richer in condensed structure, such as $\beta-5$ and 5-5 linkages, than HAL. Such carbon-carbon bonds would suppress rotational motion of aromatic rings in lignin, leading to low thermal mobility. SAL was able to be converted to fusible material by elimination of highmolecular-mass fraction or by re-cooking SAL with aqueous acetic acid to encourage the cleavage of residual aryl-ether bond [40]. Polyethylene glycol (PEG)-lignin from cedar is an exceptionally fusible softwood lignin [41]. It had a low glass transition temperature and a thermal-flow temperature. This fusibility was also derived from PEG moiety, the content of which accounted for more than $40 \%$ of the lignin.

Based on the relationship between lignin fusibility and thermal motion of the aromatic ring, infusible lignin from steam explosion of hardwood was successfully able to be converted to fusible lignin by phenolation [42]. Similarly, the fusibility of cresol lignin and lignophenol [43] should also be brought about by the introduced aromatic moiety in the pulping or separation process of wood components.

\section{Thermal molding of lignins}

Fusible polymers are easily transformed into fiber, film, and other moldings by thermal processing. Also, fusible lignins can be transformed into fibers by melt spinning [44, 45]. However, the resultant fibers are very weak and cannot be utilized like synthetic fibers or man-made fibers. To overcome the problem and to add functionality, the lignin fibers are further converted to carbon fibers (CFs). The typical process is shown in Fig. 2.

In this $\mathrm{CF}$ production process, thermostabilization, which converts fusible lignin fibers into infusible ones, is a necessary but very tedious and time-consuming step. Without such a conversion step, fusible lignin fibers melt and lose their fibrous morphology in the following carbonization step. In general, this conversion is carried out by heating the fibers slowly up to $250-300{ }^{\circ} \mathrm{C}$ under an air or an oxygen atmosphere, where oxygen molecule incorporated in lignin acts as a cross-linker. Thermostabilization of HAL fibers was completed by heating them up to $250{ }^{\circ} \mathrm{C}$ at a heating rate of $0.5{ }^{\circ} \mathrm{C} / \mathrm{min}$ and keeping this temperature for $1 \mathrm{~h}$ (total time $>8 \mathrm{~h}$ ). Thus, saving time needed for this thermostabilization step is a key subject to produce CFs from isolated lignins.

In the case of PEG-lignin fibers, very slow heating rate was required for thermostabilization, namely, at less than $0.1{ }^{\circ} \mathrm{C} / \mathrm{min}$ (almost 2 days). As-spun fibers from a mixture of PEG-lignin and hexamethylene tetramine as a curing agent for phenol-formaldehyde resin were successfully thermostabilized at a heating rate of $2{ }^{\circ} \mathrm{C} / \mathrm{min}$ (ca. $2 \mathrm{~h}$ ). On the other hand, SAL fibers could be directly subjected to the following carbonization without thermostabilization [46]. Although infusible SAL could be converted to fusible material by re-cooking as mentioned above, the resulting SAL could barely be spun, and its spinnability was much lower than that of HAL. The low thermal mobility of SAL helped to skip a thermostabilization step.

The thermostabilized fibers were, in turn, converted to CFs by carbonization, which was conducted by heating up to $1000{ }^{\circ} \mathrm{C}$ under an inert gas atmosphere. The mechanical properties of the resultant lignin CFs are listed in Table 1, where polyacrylonitrile (PAN) is a major feedstock for CF. 
Table 1 Mechanical properties of lignin-based carbon fibers

\begin{tabular}{|c|c|c|c|c|c|}
\hline & Diameter $(\mu \mathrm{m})$ & Tensile strength (MPa) & $\operatorname{MOE}^{\mathrm{c}}(\mathrm{GPa})$ & Elongation $(\%)$ & References \\
\hline Hardwood kraft lignin & $46.0 \pm 8.0$ & $422 \pm 80$ & $40.0 \pm 11.0$ & $1.12 \pm 0.22$ & {$[52]$} \\
\hline Alcell lignin & $31.0 \pm 3.0$ & $388 \pm 123$ & $40.0 \pm 14.0$ & $1.00 \pm 0.23$ & {$[52]$} \\
\hline Exploded lignin $^{\mathrm{a}}$ & $7.6 \pm 2.7$ & $660 \pm 230$ & $40.7 \pm 6.3$ & $1.63 \pm 0.29$ & [44] \\
\hline Hardwood acetic acid lignin & $14.0 \pm 1.0$ & $355 \pm 53$ & $39.1 \pm 13.3$ & $0.98 \pm 0.25$ & {$[45]$} \\
\hline Softwood acetic acid lignin & $35.3 \pm 6.3$ & $108 \pm 65$ & - & - & {$[46]$} \\
\hline Softwood PEG-lignin & $8.2 \pm 1.0$ & $695 \pm 124$ & $47.3 \pm 11.5$ & $1.51 \pm 0.25$ & {$[41]$} \\
\hline Acetylated softwood & $6-8$ & $1040 \pm 100$ & $52 \pm 2$ & $2 \pm 0.2$ & {$[55]$} \\
\hline \multicolumn{6}{|l|}{ Kraft lignin } \\
\hline HWKL-PEO ${ }^{\mathrm{b}}$ & $44.0 \pm 4.0$ & $392 \pm 89$ & $44.0 \pm 12.0$ & $0.91 \pm 0.16$ & [37] \\
\hline Polyacrylonitrile & $5-10$ & $3500-6300$ & $200-500$ & $0.8-2.2$ & - \\
\hline
\end{tabular}

${ }^{a}$ Exploded lignin was converted into spinning raw material by hydrogenolysis followed by thermal condensation

${ }^{\mathrm{b}}$ Blend of hardwood kraft lignin and polyethylene oxide

c Modulus of elasticity

The lignin-based CFs are much weaker than the PANbased counterparts. The reason would be attributed to the existence of non-graphitized carbon derived from lignin and cellulose. Therefore, the lignin CFs are utilized only in a limited area [47]. To expand the application, lignin should be converted to a graphitable carbon-rich compound like mesophase pitch [48].

To use such weak CFs from lignin, further functionalization was attempted. Production of activated carbon fibers (ACFs) was one of the representative examples. The ACFs with large surface area are a promising electrode material for second battery and electric double-layer capacitor, which is described later, in addition to the environmental purification agent [49-51].

\section{CF from kraft lignin}

We considered about 20 years ago that softwood and hardwood kraft lignins (SKL and HKL, respectively) would not show fusibility, because no thermally active compound was introduced to lignin in the kraft pulping process. However, melt spinning of HKL was developed by Kadla and his coworkers in 2002 [52]. Although there still is no report on melt spinning of SKL alone, its spinning was achieved by the addition of low-molecular-mass fraction of hardwood kraft lignin in 2013 [53]. The SKLbased fibers could be thermostabilized at a heating rate of $3{ }^{\circ} \mathrm{C} / \mathrm{min}$. In addition, this research group successfully spun fibers from SKL alone, which was a low-molecularmass fraction of SKL prepared by ultrafiltration, and the thermostabilization of the resulting fibers was achieved at a heating rate of $15^{\circ} \mathrm{C} / \mathrm{min}$ [54]. Last year, $\mathrm{CF}$ with a tensile strength of more than $1 \mathrm{GPa}$, was first prepared from partially acetylated SKL through dry spinning [55]. Thus, most of the isolated lignins can be a feedstock for CF.

\section{Fusibility of polymeric lignin model compounds}

Here, we prompt a question: if lignin does not have condensed structure or lignin is comprised exclusively of $\beta$-O4 linkage, which is the major linkage in lignin, then does such lignin show thermal fusibility? To clarify this point, our research group investigated the fusibility of polymeric lignin models, namely C6-C2 [56] and C6-C3 models [57] (Fig. 3).

C6-C2 type of polymeric model compound showed fusibility, but C6-C3 type did not. When the hydroxy group at the $\mathrm{C} \gamma$ position of the $\mathrm{C} 6-\mathrm{C} 3$ type model was modified to ester or carboxylate, the modified model underwent thermal flow. Fourier-transfer infrared spectroscopic (FT-IR) analysis demonstrated that the $\mathrm{C} \gamma$ hydroxy group formed intermolecular hydrogen bond, resulting in low thermal mobility of the C6-C3 type model [58]. From this finding, fusibility and thermal mobility of kraft lignins would probably be caused by the elimination of the $\mathrm{C} \gamma$ hydroxy (methylol) group in the pulping process [59].

\section{Electrospun fibers of lignin and their applications}

Electrospinning developed in 1930s [60] is one of traditional spinning methods, but it draws much attention as a fascinating method to produce nanofibers. In this method, there are three types of procedures, wet, dry and melt electrospinnings. Most of the isolated lignins can dissolve in general solvents, such as aqueous alkaline solution and organic solvents. Therefore, those lignins can be easily transformed into nanofiber mat by wet electrospinning and dry electrospinning [61, 62]. Their applications have also been proposed, such as in carbonaceous materials, filter and electrode [63-65]. Therefore, fabrication of ligninderived fibers has been a hot topic for this decade. 


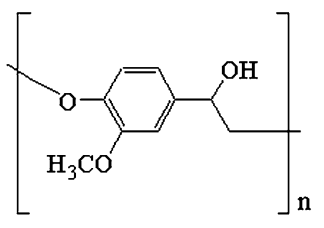

1

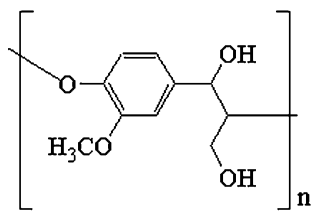

2

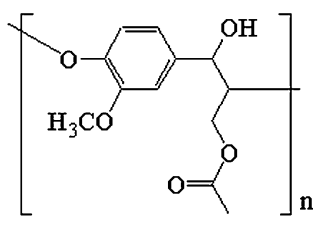

3

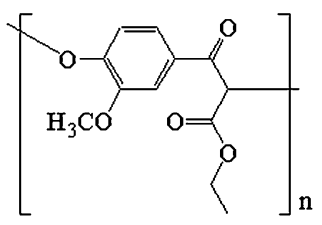

4

Fig. 3 Chemical structures of polymeric lignin models. 1 C6-C2 type model, 2 C6-C3 type model, 3 acetylated C6-C3 type model, 4 C6-C3 type of carboxylate model

However, wet electrospinning of isolated lignins has not been reported so far.

\section{Lignin resin}

The production of phenol-formaldehyde resin from lignin has been a very traditional research subject, and it has still been one of the current research subjects for lignin utilization $[66,67]$. Polyurethane resin from lignin has been a well-studied polymer. Since hydroxy groups of general isolated lignins have low reactivity, hydroxypropylation of the lignins with propylene oxide [68] was conducted to convert them into modified lignin preparations for polymerization $[69,70]$. There are also some reports on the preparations of lignin-based polyesters [71] and epoxy resins [72]. However, these lignin-based polymers or resins have not been effectively used yet. Only lignin polyurethane has been utilized as an insulate material in domestic houses in Japan [73]. Recently, Kubota et al. developed porous lignin-based polyester from softwood PEG-lignin, which had have opened new application as a separator for electric double-layer capacitor (EDLC) [74].

\section{Future outlook}

Nowadays, drilling technologies for shale gas and oil have been developed and established. It looks, then, probable that fossil resources will be supplied stably during this century. Consequently, a steep rise in price of petroleum, which I. S. Goldstein [1] feared, seems not likely to occur in the near future. In this situation, wood components should be converted not only to conventional resins or plastics from a viewpoint of reduced environmental impact, but also to value-added, highly functional materials with respect to reduced production cost. Recently stimuli-responsive and unique functional polymers have been developed from lignin by graft polymerization of atomic transfer radical polymerization (ATRP) [75-77]. This is one of the examples of highly functional material. Based on the fact that isolated lignins have the largest carbon content among wood components, new types of carbonaceous material including carbon fibers have been fabricated from lignin, especially for electrodes of second battery [78] and EDLC [79, 80]. These products seem to be promising, value-added, lignin-based materials developed in this century.

Furthermore, pulp consumption is decreased these days, while pulp production is excessive worldwide. Some pulp and paper mills in the USA quit pulp production. Bioethanol production from excess cellulose can be a solution to this problem. However, since cellulose can be a feedstock for vinyl polymer [1], the research and development of smart functional polymers from cellulose and pulp as sensor, intelligent materials, and medical goods will/must also be accelerated by their modification with living radical polymerization including atom transfer radical polymerization [81, 82]. Similarly, hemicelluloses will draw attention as a feedstock not only as fuel and aforementioned resins, but also as dietary fibers [83].

To achieve comprehensive utilization of wood components, it is expected to establish effective and efficient biorefinery processes of lignocellulose.

\section{References}

1. Goldstein IS (1975) Potential for converting wood into plastics Chemicals from wood may regain importance as the cost of petroleum continues to rise. Science 189:847-852

2. Kondo Y, Takeda A, Hideshima S (1959) Effect of admixtures on electrolytic corrosion of steel bars in reinforced concrete. J Am Concr Inst 31:299-312

3. Sohn AW, Erasmus A (1969) Lead electrodes having embedded, lignosulfonate-coated particles. US Pat 3480478 A

4. Iwamoto S, Nakagaito AN, Yano H, Nogi M (2005) Optically transparent composites reinforced with plant fiber-based nanofibers. Appl Phys A-Mater Sci Process 81:1109-1112

5. Nogi M, Iwamoto S, Nakagaito AN, Yano H (2009) Optically transparent nanofiber paper. Adv Mater 21:1595-1598

6. Kondo T, Kose R, Naito H, Kasai W (2014) Aqueous counter collision using paired water jets as a novel means of preparing bio-nanofibers. Carbohydr Polym 112:284-290

7. Saito T, Kimura S, Nishiyama Y, Isogai A (2007) Cellulose nanofibers prepared by TEMPO-mediated oxidation of native cellulose. Biomacromolecules 8:2485-2491

8. Kuramae R, Saito T, Isogai A (2014) TEMPO-oxidized cellulose nanofibrils prepared from various plant holocelluloses. React Funct Polym 85:126-133 
9. Glasser WG, Kaar WE, Jain RK, Sealey JE (2000) Isolation options for non-cellulosic heteropolysaccharides (hetps). Cellulose 7:299-317

10. Heinze T, Koschell, A, Ebringerova A (2004) Chemical functionalization of xylan: A short review. In: Gatenholm P, Tenkanen M (eds) Hemicelluloses: Science and Technology. ACS Symposium Series 864, American Chemical Society, Washington, pp 312-325

11. Hansen NML, Plackett D (2008) Sustainable films and coatings from hemicelluloses: a review. Biomacromolecules 9:1493-1505

12. Sun RC, Fang JM, Tomkinson J, Jones GL (1999) Acetylation of wheat straw hemicelluloses in $\mathrm{N}, \mathrm{N}$-dimethylacetamide/ $\mathrm{LiCl}$ solvent system. Ind Crop Prod 10:209-218

13. Sun RC, Fang JM, Tomkinson J (2000) Stearoylation of hemicelluloses from wheat straw. Polym Degrad Stab 67:345-353

14. Sun XF, Sun RC, Sun JX (2004) Oleoylation of sugarcane bagasse hemicelluloses using $N$-bromosuccinimide as a catalyst. J Sci Food Agric 84:800-810

15. Sun XF, Sun RC, Zhao L, Sun JX (2004) Acetylation of sugarcane bagasse hemicelluloses under mild reaction conditions by using NBS as a catalyst. J Appl Polym Sci 92:53-61

16. Buchanan CM, Buchanan NL, Debenham JS, Gatenholm P, Jacobsson M, Shelton MC, Watterson TL, Wood MD (2003) Preparation and characterization of arabinoxylan esters and arabinoxylan ester/cellulose ester polymer blends. Carbohydr Polym $52: 345-357$

17. Fundador NGV, Enomoto-Rogers $\mathrm{Y}$, Takemura $\mathrm{A}$, Iwata $\mathrm{T}$ (2012) Acetylation and characterization of xylan from hardwood kraft pulp. Carbohydr Polym 87:170-176

18. Fundador NGV, Enomoto-Rogers Y, Takemura A, Iwata $\mathrm{T}$ (2012) Syntheses and characterization of xylan esters. Polymer 53:3885-3893

19. Fundador NGV, Enomoto-Rogers Y, Takemura A, Iwata T (2013) Xylan esters as bio-based nucleating agents for poly (Llactic acid). Polym Degrad Stab 98:1064-1071

20. Fundador NGV, Iwata T (2013) Enhanced crystallization of poly (D-lactide) by xylan esters. Polym Degrad Stab 98:2482-2487

21. Enomoto-Rogers Y, Iwata T (2012) Synthesis of xylan-graftpoly(L-lactide) copolymers via click chemistry and their thermal properties. Carbohydr Polym 87:1933-1940

22. Enomoto-Rogers Y, Iwata T (2013) Syntheses of poly(L-lactide)block-xylan butyrate-block-poly(L-lactide) triblock copolymers and their properties. J Wood Sci 59:489-498. doi:10.1007/ s10086-013-1367-X

23. Enomoto-Rogers Y, Ohmoto Y, Takemura A, Iwata T (2014) Synthesis of glucomannan esters and their thermal and mechanical properties. Carbohydr Polym 101:592-599

24. Danjo T, Enomoto-Rogers Y, Takemura A, Iwata T (2014) Syntheses and properties of glucomannan acetate butyrate mixed esters. Polym Degrad Stab 109:373-378

25. Yang $T$, He W, Wang $S$, Song $X$ (2014) $\mathrm{H}_{2} \mathrm{O}_{2}$ oxidation of corncob holocellulose as a dry-strength additive for paper. BioResources 9:7267-7277

26. Wang M, He W, Wang S, Song X (2015) Carboxymethylated glucomannan as paper strengthening agent. Carbohydr Polym 125:334-339

27. Yang H, Wang K, Song X, Xu F (2011) Production of xylooligosaccharides by xylanase from Pichia stipitis based on xylan preparation from triploid Populus tomentosa. Bioresour Technol 102:7171-7176

28. Song X, Hubbe MA (2014) TEMPO-mediated oxidation of oat $\beta$ D-glucan and its influences on paper properties. Carbohydr Polym 99:617-623

29. Song X, Hubbe MA (2014) Enhancement of paper dry strength by carboxymethylated $\beta$-D-glucan from oat as additive. Holzforschung 68:257-263
30. Lindblad MS, Albertsson A-C, Ranucci E, Laus M, Giani E (2005) Biodegradable polymers from renewable sources: rheological characterization of hemicellulose-based hydrogels. Biomacromolecules 6:684-690

31. Hartman J, Albertsson A-C, Sjöberg J (2006) Surface- and bulkmodified galactoglucomannan hemicellulose films and film laminates for versatile oxygen barriers. Biomacromolecules 7:1983-1989

32. Bigand V, Pinel C, Perez DDS, Rataboul F, Huber P, Petit-Conil M (2011) Cationisation of galactomannan and xylan hemicelluloses. Carbohydr Polym 85:138-148

33. Voepel J, Edlund U, Albertsson A-C (2011) A versatile singleelectron-transfer mediated living radical polymerization route to galactoglucomannan graft-copolymers with tunable hydrophilicity. J Polym Sci Part A Polym Chem 49:2366-2372

34. Maeda H (1942) Lignosulfonic acid. I. Surface activity of lignosulfonic acid. Kogyo Kagaku Zasshi 45:267-272

35. Ge Y, Li D, Li Z (2014) Effects of lignosulfonate structure on the surface activity and wettability to a hydrophobic powder. BioResources 9:7119-7127

36. Kubo S, Uraki Y, Sano Y (1996) Thermomechanical analysis of isolated lignins. Holzforschung 50:144-150

37. Kubo S, Kadla JF (2004) Poly(ethylene oxide)/organosolv lignin blends: relationship between thermal properties, chemical structure, and blend behavior. Macromolecules 37:6904-6911

38. Sano Y, Sasaya T, Sakakibara A (1988) Solvolysis pulping of hardwoods. Kami Pa Gikyoshi 42:487-496

39. Kubo S, Yamada T, Hashida K, Ono H (2007) Grafting of ethylene glycol chains in lignin during the solvolysis for biomass conversion using ethylene carbonate/ethylene glycol system. Chem Lett 36:502-503

40. Kubo S, Ishikawa N, Uraki Y, Sano Y (1997) Preparation of lignin fibers from softwood acetic acid lignin: relationship between fusibility and the chemical structure of lignin. Mokuzai Gakkaishi 43:655-662

41. Lin J, Kubo S, Yamada T, Koda K, Uraki Y (2012) Chemical thermostabilization for the preparation of carbon fibers from softwood lignin. BioResources 7:5634-5646

42. Sudo K, Shimizu K, Nakashima N, Yokoyama A (1993) A new modification method of exploded lignin for the preparation of a carbon fiber precursor. J Appl Polym Sci 48:1485-1491

43. Aoyagi M, Funaoka M (2010) Thermal responses of lignophenols. Trans Mater Res Soc Jpn 35:967-970

44. Sudo K, Shimizu K (1992) New carbon fiber from lignin. J Appl Polym Sci 44:127-134

45. Uraki Y, Kubo S, Nigo N, Sano Y, Sasaya T (1995) Preparation of carbon fibers from organosolv lignin obtained by aqueous acetic acid pulping. Holzforschung 49:343-350

46. Kubo S, Uraki Y, Sano Y (1998) Preparation of carbon fibers from softwood lignin by atmospheric acetic acid pulping. Carbon 36:1119-1124

47. Baker DA, Rials TG (2013) Recent advances in low-cost carbon fiber manufacture from lignin. J Appl Polym Sci 130:713-728

48. Mochida I, Korai Y, Wang YG, Hong SH (2001) Preparation and properties of mesophase pitches. World Carbon 1:221-247

49. Uraki Y, Kubo S, Kurakami H, Sano Y (1997) Activated carbon fibers from acetic acid lignin. Holzforschung 51:188-192

50. Uraki Y, Nakatani A, Kubo S, Sano Y (2001) Preparation of activated carbon fibers with large specific surface area from softwood acetic acid lignin. J Wood Sci 47:465-469

51. Lin J, Kubo S, Yamada T, Koda K, Uraki Y (2012) Chemical thermostabilization for the preparation of carbon fibers from softwood lignin. BioResources 7:5634-5646

52. Kadla JF, Kubo S, Venditti RA, Gilbert RD, Compere AL, Griffith W (2002) Lignin-based carbon fibers for composite fiber applications. Carbon 40:2913-2920 
53. Nordström Y, Norberg I, Sjöholm E, Drougge R (2013) A new softening agent for melt spinning of softwood kraft lignin. J Appl Polym Sci 129:1274-1279

54. Norberg I, Nordström Y, Drougge R, Gellerstedt G, Sjöholm E (2013) A new method for stabilizing softwood kraft lignin fibers for carbon fiber production. J Appl Polym Sci 128:3824-3830

55. Zhang M, Ogale AA (2014) Carbon fibers from dry-spinning of acetylated softwood kraft lignin. Carbon 69:626-629

56. Kishimoto T, Uraki Y, Ubukata M (2005) Easy synthesis of $\beta-O-$ 4 type lignin related polymers. Org Biomol Chem 3:1067-1073

57. Kishimoto T, Uraki Y, Ubukata M (2006) Chemical synthesis of $\beta-O-4$ type artificial lignin. Org Biomol Chem 4:1343-1347

58. Uraki Y, Sugiyama Y, Koda K, Kubo S, Kishimoto T, Kadla JF (2012) Thermal mobility of $\beta$-O-4-type artificial lignin. Biomacromolecules 13:867-872

59. Gierer J (1970) The reaction of lignin during pulping. A description and comparison of conventional pulping processes. Svensk Papperstidn 73:571-596

60. Formhals A (1934) Process and apparatus for preparing artificial threads. US Pat 1(975):504

61. Lallave M, Bedia J, Ruiz-Rosas R, Rodriguez-Mirasol J, Cordero T, Otero JC, Marquez M, Barrero A, Loscertales IG (2007) Filled and hollow carbon nanofibers by coaxial electrospinning of Alcell lignin without binder polymers. Adv Mater 19:4292-4296

62. Dallmeyer I, Ko F, Kadla JF (2010) Electrospinning of technical lignins for the production of fibrous networks. J Wood Chem Technol 30:315-329

63. Jin J, Yu BJ, Shi ZQ, Wang CY, Chong CB (2014) Lignin-based electrospun carbon nanofibrous webs as free-standing and binderfree electrodes for sodium ion batteries. J Power Sources 272:800-807

64. Lai C, Kolla P, Zhao Y, Fong H, Smirnova A (2014) Ligninderived electrospun carbon nanofiber mats with supercritically deposited $\mathrm{Ag}$ nanoparticles for oxygen reduction reaction in alkaline fuel cells. Electrochim Act 130:431-438

65. You X, Koda K, Yamada T, Uraki Y (2015) Preparation of electrode for electric double layer capacitor from electrospun lignin fibers. Holzforschung. doi:10.1515/hf-2014-0262

66. Qiao W, Li S, Guo G, Han S, Ren S, Ma Y (2015) Synthesis and characterization of phenol-formaldehyde resin using enzymatic hydrolysis lignin. J Ind Eng Chem 21:1417-1422

67. Guo Z, Liu Z, Ye L, Ge K, Zhao T (2015) The production of lignin-phenol-formaldehyde resin derived carbon fibers stabilized by BN preceramic polymer. Mater Lett 142:49-51

68. Jain RK, Glasser WG (1993) Lignin derivatives II. Functional ethers. Holzforschung 47:325-332

69. Toffey A, Glasser WG (1997) Cure characterization of polyurethanes with lignin and cellulose derivatives. Holzforschung 51:71-78

70. Li Y, Ragauskas AJ (2012) Kraft lignin-based rigid polyurethane foam. J Wood Chem Technol 32:210-224
71. Li H, Sivasankarapillai G, McDonald AG (2015) Lignin valorization by forming toughened thermally stimulated shape memory copolymeric elastomers: Evaluation of different fractionated industrial lignins. J Appl Polym Sci. doi:10.1002/APP. 41389

72. Ismail TNMT, Hassan HA, Hirose S, Taguchi Y, Hatakeyama T, Hatakeyama H (2010) Synthesis and thermal properties of estertype crosslinked epoxy resins derived from lignosulfonate and glycerol. Polym Int 59:181-186

73. Hasegawa T, Wakisaka $\mathrm{O}$ (2006) Non-combustible polyurethane foam insulation (in Japanese). Jpn Pat 2006-326943

74. Kubota A, Isozaki T, Yamada T, Koda K, Uraki Y (2014) Preparation and application of a new polyester film from cedarorganosolv lignin (in Japanese with English abstract). In: Proceedings the 59th lignin symposium, Fukui, Japan, pp 46-49

75. Kim YS, Kadla JF (2010) Preparation of a thermoresponsive lignin-based biomaterial through atom transfer radical polymerization. Biomacromolecules 11:981-988

76. Gao G, Dallmeyer JI, Kadla JF (2012) Synthesis of lignin nanofibers with ionic-responsive shells: water-expandable ligninbased nanofibrous mats. Biomacromolecules 13:3602-3610

77. Liu X, Yin H, Diao B, Zhang Z, Li J (2015) Functionalization of lignin through ATRP grafting of poly(2-dimethylaminoethyl methacrylate) for gene delivery. Colloids Surf B- Biointerfaces 125:230-237

78. Rios O, Martha SK, McGuire MA, Tenhaeff W, More K, Daniel C, Nanda J (2014) Monolithic composite electrodes comprising silicon nanoparticles embedded in lignin-derived carbon fibers for lithium-ion batteries. Energy Technol 2:773-777

79. Hu S, Zhang S, Pan N, Hsieh YL (2014) High energy density supercapacitors from lignin derived submicron activated carbon fibers in aqueous electrolytes. J Power Sources 270:106-112

80. Jeon JW, Zhang L, Lutkenhaus JL, Laskar DD, Lemmon JP, Choi D, Nandasiri MI, Hashmi A, Xu J, Motkuri RK, Fernandez CA, Liu J, Tucker MP, McGrail PB, Yang B, Nune SK (2015) Controlling porosity in lignin-derived nanoporous carbon for supercapacitor applications. Chem Sus Chem 8:428-432

81. Joubert F, Musa OM, Hodgson DRW, Cameron NR (2014) The preparation of graft copolymers of cellulose and cellulose derivatives using ATRP under homogeneous reaction conditions. Chem Soc Rev 43:7217-7235

82. Hufendiek A, Trouillet V, Meier MAR, Barner-Kowollik C (2014) Temperature responsive cellulose-graft-copolymers via cellulose functionalization in an ionic liquid and RAFT polymerization. Biomacromolecules 15:2563-2572

83. Godin B, Agneessens R, Gerin P, Delcarte J (2014) Structural carbohydrates in a plant biomass: correlations between the detergent fiber and dietary fiber methods. J Agric Food Chem 62:5609-5616 